\title{
A profile of older community-dwelling home care clients with heart failure in Ontario
}

\author{
A. D. Foebel, MSc (1); J. P. Hirdes, PhD (1,2); G. A. Heckman, MD, MSc (1,3); S. L. Tyas, PhD (1,4); E. Y. Tjam, PhD (1,5)
}

\begin{abstract}
Introduction: The aging of the Canadian population is associated with a rising burden of heart failure (HF), a condition associated with significant morbidity, mortality and health service use.
\end{abstract}

Methods: We used data from the Ontario Resident Assessment Instrument-Home Care database for all long-stay home care clients aged 65 years or older to (1) describe the demographic and clinical characteristics of home care clients with HF and (2) examine service use among home care clients with HF to promote management at home with appropriate services.

Results: Compared with other home care clients, HF clients exhibit more health instability, take more medications, experience more comorbid conditions and receive significantly more nursing, homemaking and meal services. They are hospitalized more frequently, have significantly more emergency department visits and use more emergent care.

Discussion: HF clients are a more complex group than home care clients in general. Patient self-care must be tailored to the clinical characteristics, patterns of service use and barriers to self-care of the client. This is particularly true for older, frail and medically complex HF patients, many of whom require home care services. This work provides a background upon which to base initiatives to help these higher-needs clients manage their HF at home with appropriate support and services.

Keywords: heart failure, chronic disease, home care, interRAI, disease management, self-care, Ontario Resident Assessment Instrument-Home Care, older adults.

\section{Introduction}

Heart failure (HF) is a "complex syndrome in which abnormal heart function results in, or increases the subsequent risk of, clinical symptoms and signs of low cardiac output and/or pulmonary or systemic conges-

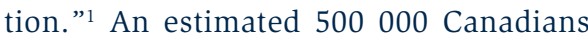
live with $\mathrm{HF}^{2}$ and its prevalence increases with age. ${ }^{3}$ At age 80 , both men and women have approximately a $20 \%$ lifetime risk of developing $\mathrm{HF}^{3}$ Population aging and improved survival of patients with hypertension and myocardial infarction, two important risk factors for $\mathrm{HF}$, contribute to the rising prevalence of $\mathrm{HF}^{4,5}$ mortality rates as high as $50 \%$, and $25 \%$ to $40 \%$ of patients will die within one year of diagnosis. ${ }^{1,9} \mathrm{HF}$ patients today are primarily 65 years or older and suffer from multiple comorbidities including hypertension, diabetes, arthritis, cognitive impairment and depression. ${ }^{10,11}$

The prevalence of HF translates into high costs for the Canadian health care system. The repeated hospitalizations, complex treatment regimen and cost of pharmacotherapy strain many components of health care including primary and specialty care, emergency departments (ED) and hospitals. ${ }^{12}$ Among Canadians over 85 years of age, HF is responsible for more hospitalizations than ischemic heart disease or heart attack. ${ }^{8}$ Readmission rates for disease complications can reach $33 \%$ within three to six months; ${ }^{13}$ patients with HF are re-admitted because of poor clinical status, which may continue to worsen in hospital. Hospitalization itself, in fact, appears to lead to progressive functional decline and eventual placement into a long-term care (LTC) facility; ${ }^{14-16}$ over $10 \%$ of hospitalizations of older adults resulting in an Alternate Level of Care designation are for cardiovascular disease, particularly $\mathrm{HF}$, as are up to $20 \%$ of transfers of LTC residents to hospital. ${ }^{17,18}$ LTC residents hospitalized with HF may experience long ED waits and spend on average six days in hospital. ${ }^{18}$ Further, $7.4 \%$ of LTC residents hospitalized for HF remain in hospital as Alternate Level of Care patients awaiting transfer back to their LTC home. ${ }^{18}$ Such admissions are often unsuitable and potentially preventable if HF were better managed in primary care. ${ }^{19-23}$ Specifically, the health care system

1. Department of Health Studies and Gerontology, University of Waterloo, Waterloo, Ontario, Canada

2. Homewood Research Institute, Guelph, Ontario, Canada

3. Department of Medicine, Division of Geriatrics McMaster University, Hamilton, Ontario, Canada

4. Department of Psychology, University of Waterloo, Waterloo, Ontario, Canada

5. St. Mary's General Hospital, Kitchener, Ontario, Canada

Correspondence: Andrea Foebel, Department of Health Studies and Gerontology, University of Waterloo, 200 University Ave. West, Waterloo, Ontario, Canada N2L 3G1;

Tel.: (519) 888-4567 ext. 37859; Fax: (519) 746-4657;

Email: adfoebel@mailservices.uwaterloo.ca 
needs new approaches for the management of HF targeted towards reducing the risk and duration of hospitalizations. ${ }^{?}$

Effective management of HF is challenging as it involves complex pharmacotherapeutic regimens, periodic adjustment of medication doses, elaborate dietary and fluid intake regimens, exercise therapy, and ongoing patient education to ensure appropriate self-care. The Canadian Heart Health Strategy and Action Plan recommends the Chronic Disease Management (CDM) model as the preferred model for care delivery for cardiovascular disease. ${ }^{24} \mathrm{~A}$ fundamental characteristic of $\mathrm{CDM}$ is patient-centered emphasis on disease self-care, which incorporates both self-maintenance and self-management. Self-maintenance requires adherence to prescribed treatments and health practices, ${ }^{25}$ while self-management builds on self-maintenance and includes recognition of signs and symptoms of HF, evaluation of the importance of these signs and symptoms, implementation of a treatment option and evaluation of the treatment chosen..$^{25,26}$ Self-management requires learning skills, insight, judgment, problem-solving and decision-making, and is more cognitively demanding than self-maintenance. CDM programs targeting $\mathrm{HF}$ strive to promote patient self-care; they have been shown to improve quality of life and functional status, reduce unplanned and repeated hospitalizations, and possibly reduce mortality. ${ }^{27,28}$ However, HF in older patients is often associated with multiple medical comorbidities and polypharmacy, as well as with depression and cognitive impairment, all of which can interfere with self-care and prevent patients from fully benefitting from CDM programs. ${ }^{29,30}$ Further, there is no clear understanding of the ideal duration of such programs or the most effective mode of follow-up. ${ }^{28,31}$

Given the high prevalence of HF in populations over 65 years old, the acute health care system needs enhanced CDM for HF to ease the burden on itself. Working in partnership with primary care physicians and specialty HF clinics, home care is a potentially important component of CDM for $\mathrm{HF}$ and may also provide a means of follow-up beyond the initial program. ${ }^{32}$ Developing methodologies to assess levels of risk, identify barriers to self-care, and deliver specific community-based interventions to home care clients with HF would make a significant contribution to an overall CDM strategy for HF.

HF is a common disease, but there is little research on the demographic and clinical characteristics, service use and needs of these clients in home care. This study seeks to (1) describe the demographic and clinical characteristics of long-stay home care clients with HF and (2) examine service use among long-stay home care clients with HF to promote management at home with appropriate services.

\section{Methods}

\section{Data Source}

We retrieved demographic, clinical and service use data from the Ontario Resident Assessment Instrument-Home Care (RAI-HC) database, a repository of all completed RAI-HC assessments in Ontario, a province of approximately 13.2 million people. The RAI-HC evaluates the care needs of all long-stay home care clients in the province, i.e. those expected to receive services for longer than 60 days. The assessment consists of over 300 questions designed to generate Client Assessment Protocols (CAPs) that help with further assessment and care planning, as well as to provide outcome measures for cognition, depression and physical function. Trained clinicians conduct the RAI-HC assessments and use clinical judgment to record diagnoses; they verify the accuracy of the recorded information through discussions with physicians, family and caregivers, and review medical records if necessary. The RAI-HC is considered both reliable and valid, and the items contained within have excellent inter-rater and test-retest reliability. ${ }^{33-36}$ The RAI-HC database contains detailed clinical and demographic information observed in the previous 7 days, including cognitive status, mood and behaviour patterns, informal support services, physical function, clinical diagnoses, prescription and non-prescription medication use, and acute service utilization in the previous 90 days, including hospitalizations and ED visits. This breadth of information provides a comprehensive description of all long-stay home care clients within Ontario.

\section{Sample}

All home care clients aged 65 years or older who received their most recent RAI-HC assessment between January 2004 and December 2007 were eligible for this analysis, regardless of functional or cognitive status, or presence of comorbidity $(\mathrm{N}=264$ 030). Using only the most recent assessment allowed for a prevalence sample, providing a comprehensive profile of HF clients in home care. Assessments took place either in a community or hospital setting; this study included only clients assessed in the community.

The Office of Research at the University of Waterloo provided ethics approval for our analyses of the anonymized data.

\section{Measures}

The RAI-HC includes valid and reliable items to assess HF (as well as other conditions); ${ }^{37}$ clients were defined as having HF if this condition was recorded in the assessment. Trained assessors routinely verify this information through self-report, discussions with caregivers and health providers, review of medical records and more. Accuracy of the diagnostic and medication information collected using the interRAI instruments has also been established. ${ }^{37}$ Among individuals with HF in nursing homes and LTC facilities, the positive predictive value and sensitivity for the interRAI diagnosis of HF was greater than 0.80 compared to that found in administrative databases. ${ }^{37,38}$ Clinical measures such as ejection fraction and New York Heart Association (NYHA) class were not available from this data source.

Based on previous literature and in consultation with a geriatrician, ${ }^{*}$ we used key demographic and health-related variables to describe the HF sample, ${ }^{1,11,39,40}$ including age, gender, living arrangement, marital status, caregiver presence, caregiver stress,

* One of our research team, Dr. G. A. Heckman. 
health region within Ontario (as defined by the geographic boundaries of each of the 14 Community Care Access Centres [CCACs], which are aligned with Local Health Integration Networks in Ontario), daily pain, edema, falls, number of medications, shortness of breath, incontinence and presence of comorbidity. We used the following comorbidities to describe this sample: coronary artery disease (CAD), arthritis, diabetes, reactive airway disease (including asthma, chronic obstructive pulmonary disease [COPD] and emphysema) and hypertension. The analysis also included five health index scales for functional ability, cognition, depression and health instability. These were: (1) the Activities of Daily Living (ADL) selfperformance hierarchy scale (range 0-6); (2) the Instrumental Activities of Daily Living (IADL) scale (range 0-6); (3) the Cognitive Performance Scale (CPS) (range 0-6); (4) the Depression Rating Scale (DRS) (range 0-14); and (5) the Changes in Health, End-stage disease and Signs and Symptoms (CHESS) scale (range 0-5)..$^{35,41-44}$ Each scale has been developed and validated for use with the RAI-HC, and higher scores in each measure indicate more severe impairment. ${ }^{36,41-44}$ Using the RAI-HC, we captured and analyzed the use of nursing, homemaking, physiotherapy and meal services in the previous 7 days, and hospitalizations, ED visits and use of emergent care (defined as any unplanned visit to a non-ED health provider) in the previous 90 days.

\section{Analysis}

We collapsed scores from each of the five health index scales used (ADL, IADL, CPS, DRS and CHESS) into three levels to differentiate between levels of impairment, divided the variables for age, falls, hospitalizations, ED visits and use of emergent care into three levels, and analyzed use of nursing, homemaking, physiotherapy and meal services in the home by comparing receipt of any service versus no services. We excluded three classes of commonly used HF medications (angiotensinconverting enzyme inhibitors, angiotensin receptor blockers and beta-adrenergic receptor blockers) from the medication counts. Comorbidity and medication counts were collapsed into three and four levels, respectively. We tested for differences in characteristics between groups using unpaired, two-tailed t-tests, for variance for continuous variables using Satterthwaite's unequal variance assumption and for categorical variables using chi-square tests (significance level $p<.05$ ). Stratification by age groups addressed potential confounding of observed group differences with clinical and service use variables.

All analyses were conducted using SAS software (version 9.0, SAS Institute Inc., Cary, NC).

\section{Results}

\section{Heart failure client sample}

Between January 2004 and December 2007, the RAI-HC assessed 264030 unique clients and identified 39247 home care clients with HF $(14.9 \%)$ in total. The proportion of clients with HF in each CCAC varied significantly $(p<.0001)$ (see Figure 1 ), and was highest in the Northeast CCAC $(19.5 \%$, 2899/14907) and lowest in the Central west CCAC $(11.3 \%, 996 / 8824)$.

\section{Demographic characteristics}

Table 1 shows the demographic characteristics of clients according to the presence of HF. Given the size of the sample, most observed differences are statistically significant. Compared with clients without HF, those with HF are older (mean age 83.5 years vs. 81.8 years, standard deviation [SD] 7.5 and 7.6, respectively), less likely to be women and less likely to be living alone. More clients with HF have caregivers, but there is no significant difference in levels of caregiver stress.

\section{Clinical characteristics}

Table 2 shows the clinical characteristics of home care clients by HF status. Again, due to the large sample size most observed differences are statistically significant; only clinically significant findings are reported here. HF clients have more complex functional needs than those without HF and exhibit more health instability (as measured by the CHESS scale); as expected, they also experience significantly higher levels of edema and shortness of breath. They have less cognitive impairment, as measured by the CPS scale, although the overall proportion of HF patients with some degree of cognitive impairment is high. Prevalence of depression or a history of falls in the previous 90 days does not differ by HF status.

HF clients use more medications and have more comorbid conditions than those without HF. After exclusion of three classes

\section{FIGURE 1 \\ Variation in prevalence of heart failure by Community Care Access Centre among home care clients 65 years and over, Ontario, 2004-2007 ( $\mathrm{N}=264$ 030)}

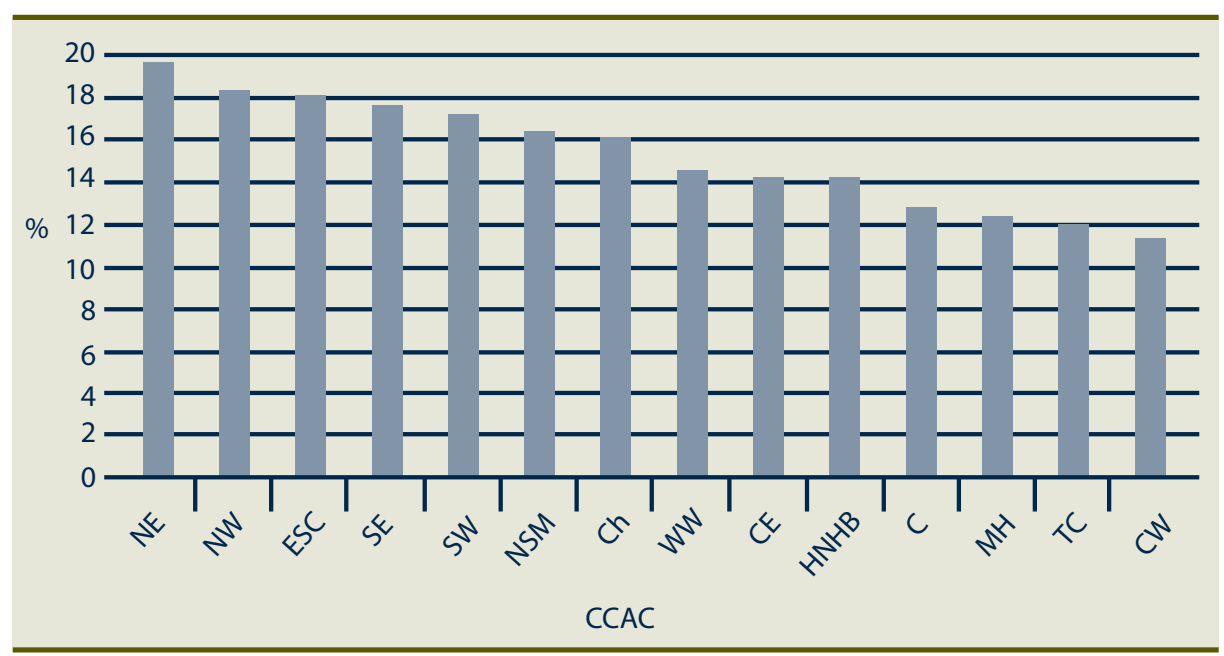

Abbreviations: C, Central; CCAC, Community Care Access Centre; CE, Central East; Ch, Champlain; CW, Central west; ESC, Erie St. Clair; HF, heart failure; HNHB, Hamilton Niagara Haldimand Brant; MH, Mississauga Halton; N, sample size; NE, Northeast; NW, Northwest; NSM, North Simcoe Muskoka; SE, Southeast; SW, Southwest; TC, Toronto Central; WW, Waterloo Wellington. 
TABLE 1

Demographic characteristics of home care clients, 65 years and older, Ontario, 2004-2007 (N = 264030$)$

\begin{tabular}{lcccc}
\hline Characteristic & & $\begin{array}{c}\text { HF sample } \\
(\mathbf{n}=\mathbf{3 9} 247) \\
\%\end{array}$ & $\begin{array}{c}\text { Non-HF sample } \\
(\mathbf{n}=224 \text { 783 })\end{array}$ & $p$-value \\
\hline Age & $65-74$ & 12.9 & 18.8 & $<.0001$ \\
& $75-84$ & 39.0 & 43.0 & \\
Gender & $85+$ & 48.1 & 38.2 & $<.0001$ \\
Married & Female & 64.1 & 66.6 & $<.0001$ \\
Living alone & & 35.0 & 38.1 & $<.0001$ \\
Caregiver available & & 32.7 & 34.5 & $<.0001$ \\
Caregiver stress & & 87.3 & 85.9 & .08 \\
\hline
\end{tabular}

Abbreviations: $\mathrm{HF}$, heart failure; $\mathrm{N}$, overall sample size; $\mathrm{n}$, sample size; $p$, statistical significance.

of medications recommended for the treatment of HF (angiotensin-converting enzyme inhibitors, angiotensin receptor blockers and beta-adrenergic receptor blockers), the mean number of medications in the HF group is $9.3(\mathrm{SD}=4.1) \mathrm{com}$ pared with $7.2(\mathrm{SD}=2.9)$ for the group without. Further, $58.0 \%$ of the HF sample take 9 or more medications compared to only $35.0 \%$ of clients without HF. Almost half the clients with HF (45.1\%) have five or more comorbid conditions, while only $26.5 \%$ of those without HF experience that level of comorbidity. Hypertension, arthritis, CAD, diabetes, osteoporosis and reactive airway disease (including COPD) are the most prevalent comorbidities in the entire sample studied. Except for osteoporosis, rates of comorbidity are higher among clients with HF. Stratification was done to explore potential confounding by age (not shown) and, apart from some variation in rates of depression and falls, there are no differences due to age for the clinical characteristics presented.

\section{Home care and acute service use}

Clients with HF receive significantly more nursing, homemaking and meal services compared with the group without HF (see Table 3), though receipt of physiotherapy services is low in both groups. Home care clients with HF received an average of 1.3 days of nursing services in the 7 days prior to RAI-HC assessment while clients without $\mathrm{HF}$ received an average of 1.0 days. $\mathrm{HF}$ clients are hospitalized more frequently, with $37.4 \%$ hospitalized more than once in the previous 90 days compared to only $26.1 \%$ of clients without HF. They also report significantly more ED visits and use more emergent care. We explored potential confounding by age using stratification, and the results do not differ from those reported in Table 3.

\section{Discussion}

Our study provides a comprehensive description of older home care clients with HF in Ontario. The extensive RAI-HC data allowed us to examine many demographic and clinical characteristics as well as service use, both through home care and acute care services. These descriptors are useful in identifying care needs as well as patterns of service use among older, communitydwelling home care clients. These analyses are also useful in identifying areas for further study or intervention strategies.

The clustering of diseases that share risk factors with HF, such as diabetes, as well as the clustering of diseases that can precipitate HF, such as hypertension and CAD, is expected among clients with HF. These data show this clustering and provide an estimate of their co-occurrence in this older cohort. The observed clustering of HF with other diseases of aging, such as arthritis and reactive airways disease, indicates that this group is more complex medically. Further, these particular comorbidities may, in the setting of a history of HF, present additional therapeutic challenges (e.g. NSAIDs for arthritis) and diagnostic challenges (e.g. dyspnea from $\mathrm{HF}$ or reactive airways).

The complex needs of the HF group are also reflected in the significantly higher levels of medication use in this group, even after adjusting to exclude three classes of medications recommended for HF. This means that these clients need to be more active in monitoring for adverse drug events as a component of their self-care.

HF clients are significantly older than their counterparts without HF. Older home care clients with HF exhibit more complex clinical characteristics than those without (Table 2); they have more health instability (as measured by the CHESS scale), are less able to look after themselves (impaired in instrumental and basic ADLs), and experience more daily pain, edema, shortness of breath and incontinence. While shortness of breath is more prevalent among HF clients, this symptom is not universal in this group, likely because such individuals are frail, and present atypically, especially among older populations. ${ }^{1,45,46}$ However, it may also be possible that such hallmark symptoms are not present in the sample due to proper management of HF through pharmacotherapy and other treatment modalities. The significantly higher prevalence of daily pain and incontinence among the HF group may represent common yet underappreciated HF manifestations,,$^{1,45}$ as may the overall higher prevalence of other comorbid conditions in this group.

Clients with HF are less likely to be severely cognitively impaired than clients without $\mathrm{HF}$, though rates of cognitive impairment are still high among both groups. Cognitive impairment in persons with $\mathrm{HF}$ is associated with a poorer outcome, including a greater risk of mortality and hospitalization, and consequently institutionalization. In a cross-sectional study such as this, people with HF and concomitant cognitive impairment may be so unable to look after themselves that they have been referred to more intensive care settings. ${ }^{30}$ Alternately, cognitive impairment may be underestimated through CPS scores, as IADL impairment is also prevalent among clients with 
TABLE 2

Clinical characteristics of home care clients based on RAI-HC assessment, 65 years and older, Ontario, 2004-2007 ( $\mathrm{N}=264$ 030)

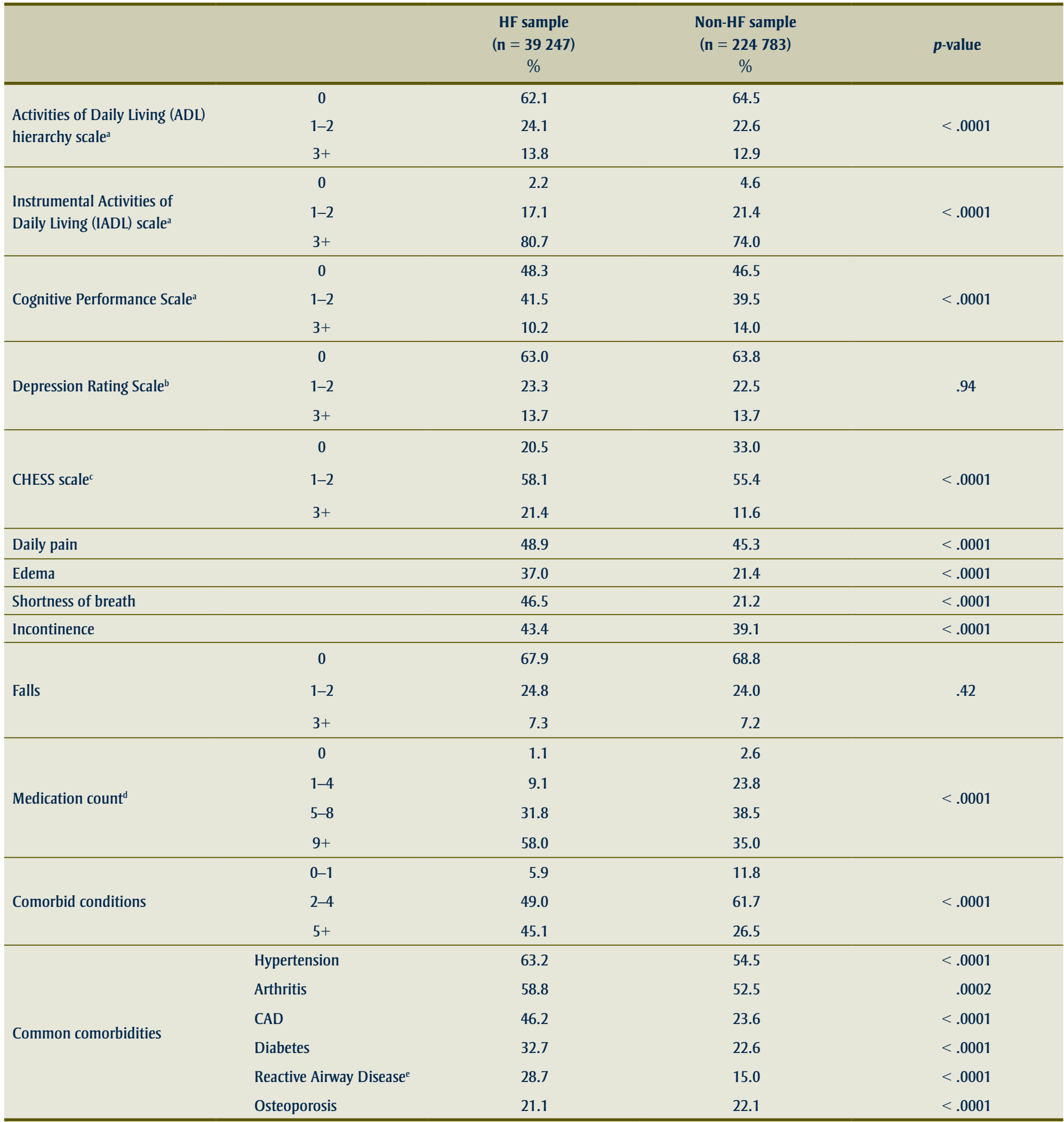

Abbreviations: CAD, Coronary Artery Disease; CHESS, Changes in Health, End-stage disease and Signs and Symptoms; HF, heart failure; N, overall sample size; $\mathrm{n}$, sample size; $p$, statistical significance; RAI-HC, Resident Assessment Instrument-Home Care.

a 0 = no impairment; $1-2=$ mild impairment; $3+=$ severe impairment.

${ }^{\mathrm{b}} 0=$ no indicators; $1-2=$ some indicators; $3+=$ many indicators.

' Changes in Health, End-stage disease and Signs and Symptoms; $0=$ no instability; $1-2=$ some instability; $3+=$ severe instability.

${ }^{d}$ Medication count excluded the following: Angiotensin-converting enzyme inhibitors (benazepril, captopril, cilazapril, enalapril, fosinopril, lisinopril, perindopril, quinapril, ramipril, trandolapril), beta-adrenergic receptor blockers (acebutolol, atenolol, bisoprolol, carvedilol, metoprolol, nadolol, propranolol) and angiotensin receptor blockers (candesartan, eprosartan, irbesartan, losartan, telmisartan, valsartan).

${ }^{\mathrm{e}}$ includes asthma, chronic obstructive pulmonary disease (COPD), and emphysema 
$\mathrm{HF}$, reflecting the presence of executive dysfunction common in this population. ${ }^{30}$ Atypical symptoms of HF in older populations may include alterations in mood and behavioural symptoms, but the similar rates of depression among HF and nonHF clients do not support this interpretation. ${ }^{46,47}$ History of falls is also similar between the two groups (Table 2), and fall prevalence is lower than reported in similar populations. ${ }^{48}$ These results indicate that the clinical complexity of HF clients receiving home care services is more apparent through functional characteristics such as ADL and IADL impairment than cognitive or depressive characteristics.

Given the clinical characteristics and medical complexity of home care clients with $\mathrm{HF}$, it is likely that there are many barriers to self-care. An indirect indication of difficulty with self-care may be the high rates of access to an informal caregiver. It is possible that without caregivers, clients with
HF are at higher risk of death or placement in an LTC facility and are thus less likely to be seen in this home care sample.

Managing multiple medical conditions and medications, and dealing with depression, cognitive impairment and functional decline are likely all barriers to effective self-care. Cognitive impairment and depressive symptoms are present in $51.7 \%$ and $37.0 \%$ of clients with $\mathrm{HF}$, respectively. Clinic-based CDM programs may not be designed to overcome such barriers to self-care, and the care setting may be inappropriate for such persons with HF. Functional impairment is high among home care clients with HF and may limit access to clinic-based programs. Further, having to schedule and attend numerous appointments for follow-up of multiple chronic conditions with many care providers may also be a barrier to attending clinic-based programs. Transitional care programs for seniors, in which specially

TABLE 3

Home care and acute health care service use among home care clients, 65 years and older, Ontario, 2004-2007 $(\mathrm{N}=264030)$

\begin{tabular}{|c|c|c|c|c|}
\hline & & $\begin{array}{c}\text { HF sample } \\
(n=39247)\end{array}$ & $\begin{array}{l}\text { Non-HF sample } \\
(n=224783)\end{array}$ & $p$-value \\
\hline & & $\%$ & $\%$ & \\
\hline \multicolumn{5}{|l|}{ Home care service use $\mathrm{u}^{\mathrm{a}, \mathrm{b}}$} \\
\hline Nursing & & 39.4 & 29.8 & $<.0001$ \\
\hline Homemaking & & 46.3 & 40.3 & $<.0001$ \\
\hline Meals & & 20.8 & 18.4 & $<.0001$ \\
\hline Physiotherapy & & 7.8 & 9.0 & $<.0001$ \\
\hline \multicolumn{5}{|c|}{ Acute health care service use $\mathrm{e}^{\mathrm{c}}$} \\
\hline \multirow{3}{*}{ Hospitalizations } & 0 & 62.6 & 74.0 & \multirow{3}{*}{$<.0001$} \\
\hline & 1 & 28.8 & 22.5 & \\
\hline & $2+$ & 8.6 & 3.6 & \\
\hline \multirow{3}{*}{ Emergency Department } & 0 & 78.1 & 81.7 & \multirow{3}{*}{$<.0001$} \\
\hline & 1 & 16.0 & 14.2 & \\
\hline & $2+$ & 5.9 & 4.1 & \\
\hline \multirow{3}{*}{ Emergent Care } & 0 & 91.2 & 92.9 & \multirow{3}{*}{$<.0001$} \\
\hline & 1 & 6.5 & 5.5 & \\
\hline & $2+$ & 2.3 & 1.6 & \\
\hline
\end{tabular}

Abbreviations: HF, heart failure; $\mathrm{N}$, overall sample size; $\mathrm{n}$, sample size; $p$, statistical significance; RAI-HC, Resident Assessment Instrument-Home Care.

a Service use measured as any vs. none.

${ }^{\mathrm{b}}$ In the seven days prior to RAI-HC assessment.

${ }^{\mathrm{C}}$ In the 90 days prior to RAI-HC assessment. trained Advanced Practice Nurses help coordinate care and enhance the self-care skills of patients with HF and their caregivers reduce readmission rates after discharge from hospital. ${ }^{49}$ However, the extension of such programs to frail home care clients with HF has not been evaluated. Home care may be a more suitable setting than LTC facilities in which to provide CDM for these medically complex clients. ${ }^{50}$ InterRAI assessment instruments used in the home care setting can offer risk assessment for adverse outcomes, identify barriers to selfcare and provide a potential platform for CDM delivery.

The geographic variation in HF prevalence is an interesting finding. Due to the standardized training given to RAI assessors throughout the province, it is unlikely that these are due to differences between raters in recording diagnoses. Given that HF risk increases with age, the age structures of the client bases of each CCAC may explain some of this variation. HF prevalence, however, is not highest in the CCACs with the oldest populations. Thus, such variations may indicate differences in access to home care services for older individuals with $\mathrm{HF}$ or, conversely, different management strategies of HF on the part of the CCAC. Some CCACs may be more likely to push for LTC admission for clients with HF, while others may promote more aggressive management within the home. There are other implications of such variations in HF prevalence, and such profiles could help CCACs prioritize service planning, initiate chronic disease management strategies and re-allocate staffing as necessary.

This descriptive work demonstrates that (1) HF is prevalent among older home care clients in Ontario and (2) clients with HF are more clinically complex, using home care and acute care more frequently than their counterparts without HF. There are some limitations to this work. First, the cross-sectional study design allows a snapshot of this sample during a given time period, but does not allow any assessment of the temporality of the associations observed. For example, we do not know whether use of services followed or preceded HF diagnosis. Further, we did not examine the reason for 
hospitalizations, ED use or emergent care use. These data indicate, however, that the more clinically complex clients with HF do indeed use more services both in the home and in the broader health care system. Additionally, these data do not include information regarding HF severity, which may influence service use, although the CHESS scale in the assessment allows some assessment of health instability and can be predictive of mortality in LTC patients. ${ }^{51}$ Clients with HF scored significantly higher on this item, indicating more disease instability overall. Another limitation is that this sample is drawn from clients already receiving home care service in Ontario and is not representative of other populations, either in institutions or in the community, that do not seek out or receive referrals for home care services. Lastly, given the demographics of this sample, it is likely that HF with preserved ejection fraction (HFPEF) is prevalent. HFPEF is more common in women and is thought to account for more than half the HF cases in those older than 75 years. ${ }^{52,53}$ Given that almost $80 \%$ of the sample with HF was older than age 75 , HFPEF likely affects a large proportion of these clients. This could not be verified from the data set used, but is worth noting as it has implications for CDM. There is much less evidence about the effectiveness of pharmacotherapy in the management of HFPEF compared to HF with reduced ejection fraction. Other aspects of HF management, however, are applicable to both populations. As better treatment modalities are identified for HFPEF, CDM programs will need to adapt accordingly.

This research has unique strengths. It provides a clear picture of the burden of $\mathrm{HF}$ in home care clients in Ontario and allows regional differences to be identified. It makes use of the extensive information available in the RAI-HC assessment to richly describe the clinical characteristics, presence of other diseases and service use in this population. Lastly, it assesses all long-stay home care clients in Ontario; since the number of HF clients identified in this sample is quite large, we can fully describe the clinical and functional characteristics of HF clients.
Our results depict home care clients with HF as a more complex, high-needs group with more medication use, more frequent use of health care services and many potential barriers to self-care, as shown by the high levels of functional impairment, cognitive impairment, depression, comorbidity and medication use. Any new CDM strategy for home care clients with HF should take these factors into consideration. Capable caregivers may have an important role to play, although programs would need to be designed to avoid undue caregiver stress. Targeting intervention strategies to improve self-care skills may significantly reduce the burden on other parts of the health care system. Improving communication between primary care providers, geriatric or cardiology consultants, and home care could allow such vulnerable populations to remain at home and independent. Such interventions would align well with the Aging at Home Strategy in Ontario, as well as with the Comprehensive Canadian Heart Health Strategy and Action Plan. An initial step to such strategies may be to identify and target the highest-needs individuals for such interventions. This work has provided a potentially important first step in achieving that goal.

\section{Acknowledgements}

The authors are grateful to the Change Foundation for financially supporting this research. Andrea D. Foebel, Erin Y. Tjam and Suzanne L. Tyas have no financial conflicts. Dr. George A. Heckman has received research funding and/or honoraria from the Heart and Stroke Foundation of Ontario, Novartis, Pfizer, and Janssen-Ortho Inc. John P. Hirdes is supported as the Ontario Home Care Research and Knowledge Exchange Chair by the Ontario Ministry of Health and Long Term Care.

\section{References}

1. Arnold JM, Liu P, Demers C, Dorian P, Giannetti N, Haddad H, Heckman GA, Howlett JG, Ignaszewski A, Johnstone DE, Jong P, McKelvie RS, Moe GW, Parker JD, Rao V, Ross HJ, Sequeira EJ, Svendsen AM, Teo K, Tsuyuki RT, White M; Canadian Cardiovascular Society. Canadian Cardiovascular Society consensus conference recommendations on heart failure 2006: diagnosis and management. Can J Cardiol. 2006;22(1):23-45.

2. Ross H, Howlett J, Arnold JO, Liu P, O’Neill B, Brophy J, Simpson C, Sholdice M, Knudtson M, Ross D, Rottger J, Glasgow $\mathrm{K}$. Treating the right patient at the right time: access to heart failure care. Can J Cardiol. 2006;22(9):749-754.

3. American Heart Association. Heart disease and stroke statistics - 2003 update [Internet]. Dallas (TX): American Heart Association; 2002 [cited 2010 Oct 25]: 1-46. Available from: http://www.americanheart. org/downloadable/heart/1059017971148200 3HDSStatsBookREV7-03.pdf

4. Curtis LH, Whellan DJ, Hammill BG, Hernandez AF, Anstrom KJ, Shea AM, Schulman KA. Incidence and prevalence of heart failure in elderly persons, 1994-2003. Arch Int Med. 2008;168(4):418-24.

5. Tu JV, Nardi L, Fang L, Liu J, Khalid L, Johansen $\mathrm{H}$; Canadian Cardiovascular Outcomes Research Team. National trends in rates of death and hospital admissions related to acute myocardial infarction, heart failure and stroke, 1994-2004. CMAJ. 2009;180:E118-E125.

6. Johansen H, Strauss B, Arnold JM, Moe G, Liu P. On the rise: the current and projected future burden of congestive heart failure hospitalization in Canada. Can J Cardiol. 2003;19(4):430-5.

7. Rouleau JL. Treatment of congestive heart failure: present and future. Can J Cardiol. 2005;21(12):1084-8.

8. Public Health Agency of Canada. Tracking heart disease and stroke in Canada. [Internet]. Ottawa (ON): Public Health Agency of Canada; 2009 [cited 2010 Oct 26]:1-132. Available from: http://www.phac-aspc.gc.ca/publicat/ 2009/cvd-avc/pdf/cvd-avs-2009-eng.pdf

9. Heart and Stroke Foundation of Canada. The changing face of heart disease and stroke in Canada 1999. Ottawa (ON): Heart and Stroke Foundation; 2000. 
10. Havranek EP, Masoudi FA, Westfall KA, Wolfe P, Ordin DL, Krumholz HM. Spectrum of heart failure in older patients: results from the National Heart Failure project. Am Heart J. 2002;143:412-7.

11. Fitchett D, Rockwood K, Chan BT, Schultz S, Bogaty P, Gillis A, Arnold M, Miller F, Graham MM, Ghali WA, Cartier R, Chow CM, Grymonpre R, Ogilvie R, Rochon P, Niznick J, Grover S, Kavanah T, Triscott J, Dafoe W, McCartney N, Rodney P, Howlett J, Chockalingam A, Dagenais G, Dalziel W, Fodor G, Goodman S, Kerr C, Power B, Murphy K. Cardiovascular Society Consensus Conference 2002: Management of heart disease in the elderly patient. Can J Cardiol. 2004;20 Suppl A:7A-16A.

12. Wilson E. Congestive heart failure: a national priority. Can J Cardiol. 2001;17(12):1243-4.

13. Tsuyuki RT, Shibata MC, Nilsson C, HervasMalo M. Contemporary burden of illness of congestive heart failure in Canada. Can J Cardiol. 2003;19(4):436-8.

14. Howlett JG, Johnstone DE, Sketris I, O’Reilly M, Horne GS, Cox JL. Identifying opportunities to address the congestive heart failure burden: the Improving Cardiovascular Outcomes in Nova Scotia (ICONS) study. Can J Cardiol. 2003;19:439-44.

15. Naylor MD. A decade of transitional care research with vulnerable elders. J Cardiovasc Nurs. 2000;14:1-14.

16. Burns RB, McCarthy EP, Moskowitz MA, Ash A, Kane RL, Finch M. Outcomes for older men and women with congestive heart failure. J Am Geriatr Soc. 1997;45:276-80.

17. Canadian Institute for Health Information. Alternate level of care in Canada [Internet]. Ottawa (ON): CIHI; 2009 Jan [cited 2010 Jan 10]:1-20. Available from: http://secure.cihi. ca/cihiweb/products/ALC_AIB_FINAL.pdf

18. Canadian Institute for Health Information. Patient pathways: transfers from continuing care to acute care. Ottawa (ON): CIHI; 2009. Report No.: ISBN: 978-1-55465-476-5.
19. Bowman CE, Elford J, Dovey J, Campbell S, Barrowclough H. Acute hospital admissions from nursing homes: some may be avoidable. Postgrad Med J. 2001;77:40-2.

20. Coburn AF, Keith RG, Bolda EJ. The impact of rural residence on multiple hospitalizations in nursing facility residents. Gerontologist. 2002;42:661-6.

21. Rizza P, Bianco A, Pavia M, Angelillo IF. Preventable hospitalization and access to primary care in an area of Southern Italy [Internet]. BMC Health Serv Res. 2007 [cited 2010 Jan 10]:7:1-8. Available from: http:// www.biomedcentral.com/1472-6963/7/134

22. Finn JC, Flicker L, Mackenzie E, Jacobs IG, Fatovich DM, Drummond S, Harris M, Holman DC, Sprivulis P. Interface between residential aged care facilities and a teaching hospital emergency department in Western Australia. Med J Aust. 2006;184:432-5.

23. Finucane P, Wundke R, Whitehead C, Williamson L, Baggoley C. Use of in-patient hospital beds by people living in residential care. Gerontology. 2000;46:133-8.

24. Smith ER, on behalf of the CHHS-AP Steering Committee. Canadian heart health strategy and action plan: building a heart healthy Canada [Internet]. Ottawa (ON): 2009 [cited 2009 Dec 14]. Available from: http://www.nwtsrc.com/content/news/ research_reports/09_chhs_report.pdf

25. Lorig KR, Holman H. Self-management education: history, definition, outcomes, and mechanisms. Ann Behav Med. 2003;26(1):1-7.

26. Phillips CO, Wright SM, Kern DE, Singa RM, Shepperd S, Rubin HR. Comprehensive discharge planning with postdischarge support for older patients with congestive heart failure: a meta-analysis. JAMA. 2004;291(11):1358-67.

27. McConaghy JR, Smith SR. Outpatient treatment of systolic heart failure. Am Fam Physician. 2004;70(11):2157-64.

28. Rich MW. Management of heart failure in the elderly. Heart Fail Rev. 2002;7(1):89-97.
29. Dickson VV, Tkacs N, Riegel B. Cognitive influences on self-care decision making in persons with heart failure. Am Heart J. 2007;154(3):424-31.

30. Heckman GA, Patterson CJ, Demers C, St. Onge J, Turpie ID, McKelvie RS. Heart failure and cognitive impairment: challenges and opportunities. Clin Interv Aging. 2007;2(2):209-18.

31. McDonald K. Disease management of chronic heart failure in the elderly: issues and options. Dis Manag Health Out. 2007;15(6):333-9.

32. Scott IA. Chronic disease management: a primer for physicians. Internal Med J. 2008; 38(6):427-37.

33. Poss JW, Jutan NM, Hirdes JP, Fries BE, Morris JN, Teare GF, Reidel K. A review of evidence on the reliability and validity of Minimum Data Set data. Healthc Manage Forum. 2008;21:33-9.

34. Hirdes JP, Ljunggren G, Morris JN, Frijters DH, Finne Soveri H, Gray L, Björkgren M, Gilgen R. Reliability of the interRAI suite of assessment instruments: a 12-country study of an integrated health information system. BMC Health Serv Res. 2008;8:277.

35. Morris JN, Fries BE, Morris SA. Scaling ADLs within the MDS. J Gerontol A Biol Sci Med Sci. 1999;54:M546-53.

36. Hartmaier SL, Sloane PD, Guess HA, Koch GG, Mitchell CM, Phillips CD. Validation of the Minimum Data Set Cognitive Performance Scale: agreement with the Mini-Mental State Examination. J Gerontol A Biol Sci Med Sci. 1995;50:M128-33.

37. Gambassi G, Landi F, Peng L, BrostrupJensen C, Calore K, Hiris J, Lipsitz L, Mor $\mathrm{V}$, Bernabei R. Validity of diagnostic and drug data in standardized nursing home resident assessments: potential for geriatric pharmacoepidemiology. SAGE Study Group. Systematic Assessment of Geriatric drug use via Epidemiology. Med Care. 1998;36(2):167-79. 
38. Wodchis WP, Naglie G, Teare GF. Validating diagnostic information on the Minimum Data Set in Ontario hospital-based longterm care. Med Care. 2008;46(8):882-7.

39. Tsuyuki RT, Ackman ML, Montague TJ; Clinical Quality Improvement Network Investigators. Effects of the 1994 Canadian Cardiovascular clinical practice guidelines for congestive heart failure. Can J Cardiol. 2002;18:147-52.

40. Heckman GA, Misiaszek B, Merali F, Turpie ID, Patterson CJ, Flett N, McKelvie RS. Management of heart failure in Canadian long-term care facilities. Can J Cardiol. 2004;20(10):963-9.

41. Hirdes JP, Frijters DH, Teare GF. The MDSCHESS scale: a new measure to predict mortality in institutionalized older people. J Am Geriatr Soc. 2003;51:96-100.

42. Morris JN, Fries BE, Mehr DR, Hawes C, Phillips C, Mor V, Lipsitz LA. MDS Cognitive Performance Scale. J Gerontol. 1994;49:M174-82.

43. Burrows AB, Morris JN, Simon SE, Hirdes JP, Phillips C. Development of a minimum data set-based depression rating scale for use in nursing homes. Age Ageing. 2000;29:165-72.

44. Landi F, Tua E, Onder G, Carrara B, Sgadari A, Rinaldi C. Minimum data set for home care: a valid instrument to assess frail older people living in the community. Med Care. 2000;38(12):1184-90.

45. Heckman GA, Demers C, McKelvie RS, Hogan DB. Heart failure in older adults. Canadian J Intern Med. 2007;2(4):24-6.

46. Rich MW. Heart failure in the 21st century: a cardiogeriatric syndrome. J Gerontol A Biol Sci Med Sci. 2001;56(2):M88-96.

47. Rockwood K. Acute confusion in elderly medical patients. J Am Geriatr Soc. 1989;37(2):150-4.
48. Cesari M, Landi F, Torre S, Onder G, Lattanzio F, Bernabei R. Prevalence and risk factors for falls in an older communitydwelling population. J Gerontol A Biol Sci Med Sci. 2002;57(8):M722-6.

49. McCauley KM, Bixby MB, Naylor MD. Advanced practice nurse strategies to improve outcomes and reduce cost in elders with heart failure. Dis Manage. 2006;9:302-10.

50. Marek KD, Popejoy L, Petroski G, Rantz M. Nurse care coordination in communitybased long-term care. J Nurs Scholarsh. 2006;38:80-6.

51. Tjam EY, Pletz DE, Hirdes JP, SJ Smith, J Costigan, B Willwerth, J Poss. Prevention of avoidable acute care use by retirement and long term care residents: management of chronic heart failure through the use of an innovative inter-disciplinary education program for care providers $(\mathrm{EPOCH}$ study). Canadian Cardiovascular Society Conference; 2006 Oct; Vancouver, BC.

52. Aronow WS. Treatment of systolic and diastolic heart failure in the elderly. J Am Med Dir Assoc. 2006;7(1):29-36.

53. Mathew ST, Gottdiener JS, Kitzman D, Aurigemma G. Congestive heart failure in the elderly: the Cardiovascular Health Study. Am J Geriatr Cardiol. 2004 Mar-Apr;13(2):61-8. 